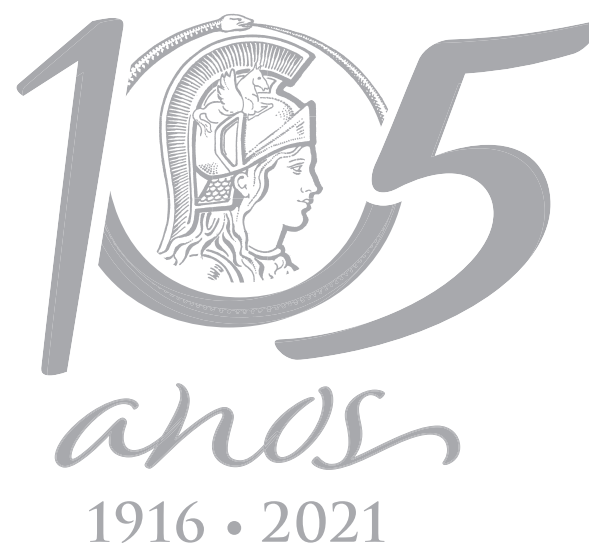

\title{
Sulfur Dioxide Derivative Prevents the Prolongation of Action Potential During the Isoproterenol-Induced Hypertrophy of Rat Cardiomyocytes
}

\author{
UĞUR DALAMAN, HASAN ÖZDOĞAN, AHMET K. SIRCAN, SEVGI A. ŞENGÜL \& \\ NAZMI YARAŞ
}

\begin{abstract}
Exogenous $\mathrm{SO}_{2}$ is toxic especially to the pulmonary and cardiovascular system, similar to nitric-oxide, carbon-monoxide, and hydrogen-sulfide. Endogenous $\mathrm{SO}_{2}$ is produced in many cell types. The $\mathrm{SO}_{2}$ content of the rat heart has been observed to substantially decrease during isoproterenol-induced hypertrophy. This study sought to determine whether an $\mathrm{SO}_{2}$ derivative could inhibit the prolongation of action potentials during the isoproterenol-induced hypertrophy of rat cardiomyocytes and explore the ionic currents. Alongside electrocardiogram recordings, the voltage and currentclamped measurements were conducted in the enzymatically isolated left ventricular cardiomyocytes of Wistar rats. The consistency of the results was evaluated by the novel mathematical electrophysiology model. Our results show that $\mathrm{SO}_{2}$ significantly blocked the prolongation of QT-interval and action potential duration. Furthermore, $\mathrm{SO}_{2}$ did not substantially affect the $\mathrm{Na}^{+}$currents and did not improve the decreased steadystate and transient outward $\mathrm{K}^{+}$currents, but it reverted the reduced L-type $\mathrm{Ca}^{2+}$ currents $\left(I_{\text {cal }}\right)$ to the physiological levels. Altered inactivation of $I_{\text {caL }}$ was remarkably recovered by $\mathrm{SO}_{2}$. Interestingly, $\mathrm{SO}_{2}$ significantly increased the $\mathrm{Ca}^{2+}$ transients in hypertrophic rat hearts. Our mathematical model also confirmed the mechanism of the $\mathrm{SO}_{2}$ effect. Our findings suggest that the shortening mechanism of $\mathrm{SO}_{2}$ is related to the $\mathrm{Ca}^{2+}$ dependent inactivation kinetics of the $\mathrm{Ca}^{2+}$ current.
\end{abstract}

Key words: Action potential, cardiomyocytes, hypertrophy, isoproterenol, rat, sulfur dioxide.

\section{INTRODUCTION}

Sulfur dioxide $\left(\mathrm{SO}_{2}\right)$ is an air pollutant and a toxic agent that has been reported to be harmful to many organs including the heart, liver, and brain (Meng 2003, Meng \& Liu 2007). However, food and manufacturing industries continue to use $\mathrm{SO}_{2}$ and its related compounds as a preservative. Ironically, $\mathrm{SO}_{2}$ can also be generated from the metabolism of sulfur-containing amino acids (Stipanuk 2004, Du et al. 2008, Luo et al. 2011), and this endogenous compound and its derivatives can alleviate various cardiovascular diseases in mammals (Jin et al. 2008, Liang et al. 2011, Zhang et al. 2011). Hence, $\mathrm{SO}_{2}$ may have opposite modulatory effects in the cardiovascular system (Huang et al. 2016b). Cysteine dioxygenase (CDO) catalyzes L-cysteine, a sulfur-containing amino acid, into L-cysteinesulfinate, which is converted by aspartate aminotransferase (AAT) to $\beta$-sulfinylpyruvate, which subsequently breaks down into pyruvate and $\mathrm{SO}_{2}$ (Stipanuk 1986).

Gasotransmitters such as carbon monoxide (CO), nitric oxide (NO), and hydrogen sulfide 
$\left(\mathrm{H}_{2} \mathrm{~S}\right)$ modulate several cellular functions either physiologically or pathophysiologically in mammals (Hermann et al. 2012). $\mathrm{SO}_{2}$ is considered to be another gasotransmitter that has ameliorating and regenerative effects on cardiovascular diseases (Huang et al. 2016a). Previous studies indicate that $\mathrm{SO}_{2}$ administration lowers systolic blood pressure, improves aortic remodeling in hypertensive rats (Zhao et al. 2008), reduces the inflammatory nuclearfactor-kB (NFKB), and the intercellular adhesion molecule-1 (ICAM-1) during hypoxic pulmonary hypertension (Sun et al. 2010). Moreover, $\mathrm{SO}_{2}$ application diminishes atherosclerotic lesions, enhances superoxide dismutase (SOD) and glutathione peroxidase (GSH-Px) activity and reduces the levels of malondialdehyde as an oxidative marker in atherosclerotic conditions (Liang et al. 2011).

Electrophysiological studies on the cardiovascular system indicate that $\mathrm{SO}_{2}$ modifies the sodium $\left(\mathrm{Na}^{+}\right)$, potassium $\left(\mathrm{K}^{+}\right)$and calcium $\left(\mathrm{Ca}^{2+}\right)$ ion channels and the functions of $\mathrm{Na}^{+} / \mathrm{Ca}^{2+}$ exchangers (NCX). The $\mathrm{Na}^{+}$current, which is one of the important currents in action potential, is increased by $\mathrm{SO}_{2}$ and its derivatives in varying concentrations (Liu et al. 2010). Moreover, $\mathrm{SO}_{2}$ derivatives shift the kinetics of voltagedependent $\mathrm{Na}^{+}$channel inactivation toward positive potentials, accelerate the period of its recovery, and alter the time-dependent recovery curve (Nie \& Meng 2005a). Another important ion current in action potential is $\mathrm{K}^{+}$, which is responsible for the repolarization and resting phase. Furthermore, $\mathrm{SO}_{2}$ and its derivatives increase the transient outward $\left(I_{\text {to }}\right)$ and inward rectifier $\left(I_{K_{1}}\right)$ potassium currents, but they do not affect the steady-state outward current $\left(I_{\text {ss }}\right)$. They also shift the activation curve toward the more negative potentials and accelerate the recovery from inactivation for $I_{\text {to }}$ (Nie \& Meng 2005b). Calcium is a dominant ion, which generates the plateau phase in action potential and acts as the crucial second messenger in many signaling pathways in physiological and pathophysiological conditions. Although there are various types of $\mathrm{Ca}^{2+}$ channels in sarcolemma, the most important one is the L-type calcium channel $\left(I_{\text {CaL }}\right)$. Interestingly, there is no consensus on the effects of $\mathrm{SO}_{2}$ on $I_{\mathrm{CaL}}$. It was found that $\mathrm{SO}_{2}$ derivatives increase the $I_{\text {CaL }}$, shift the activation and inactivation curves to more positive potentials, and accelerate the recovery from inactivation (Nie \& Meng 2006). However, another study suggests that $\mathrm{SO}_{2}$ derivatives depress the peak amplitude of $\mathrm{Ca}^{2+}$ currents, and that they do not alter the reversal potential (Zhang et al. 2011). The NCX protein provides calcium-sodium balance in the intracellular matrix not only to ensure the progression of action potential but also to eliminate the overload of free intracellular $\mathrm{Ca}^{2+}$ concentration $\left(\left[\mathrm{Ca}^{2+}\right]_{i}\right)$. While $\mathrm{SO}_{2}$ derivatives substantially reduce NCX activity, the $\left[\mathrm{Ca}^{2+}\right]_{i}$ is raised at rest (Nie \& Meng 2007).

The sympathetic adrenergic system involving the $\beta$-adrenergic receptors ( $\beta$-ARs) has chronotropic, inotropic, and lusitropic effects that are crucial in the regulation of cardiac output (Bers 2002). As $\beta$-AR signaling arranges the cardiac $\mathrm{Ca}^{2+}$ cycling and excitationcontraction coupling (ECC) in physiological conditions, it also affects the cardiac alternant, leading to pathophysiological conditions. Cardiac hypertrophy is an adaptive response mechanism to pressure or volume stress. ECC is the most affected mechanism against pressure or volume change, which involves the downregulation of $\beta$-AR signaling (Greenstein et al. 2004). Isoproterenol is a non-selective $\beta-A R$ agonist that accelerates the function of the $\beta 1$ and $\beta 2$ subtypes, and it has been widely administered in vivo in physiological or 
pathophysiological models for hypertrophic heart (Heather et al. 2009).

The $\mathrm{SO}_{2}$ content of the heart was found to decrease in an isoproterenol-induced myocardial injury model (Chen et al. 2012a). Several studies have reported that the beneficial effects of $\mathrm{SO}_{2}$ may be due to the prevention of oxidative stress in rat models (Liang et al. 2011, Chen et al. 2012a). Furthermore, $\mathrm{SO}_{2}$ reverses the deleterious effects of isoproterenol on the $\mathrm{Ca}^{2+}$ regulating protein levels in cardiomyocytes (Chen et al. 2012b) and on the ultrastructure of the myocardium (Liang et al. 2011). Despite these findings, it is still not clarified whether $\mathrm{SO}_{2}$ prevents the altered excitation of cardiomyocytes. Hence, this study aimed to investigate whether $\mathrm{SO}_{2}$ prevents the isoproterenol-induced alterations in the excitation of ventricular myocytes, and to determine the ionic currents responsible for the electrophysiological alterations.

\section{MATERIALS AND METHODS}

\section{Preparation of animals and experimental groups}

In this study, we used 3-month-old male Wistar rats weighing 250-350 g. All animals used in this study were cared for and handled following the rules of Akdeniz University's Experimental Animals Ethics Committee. Four experimental groups were defined as Control, isoproterenol-treated (ISO), isoproterenol and sodium metabisulfite-treated ( $\mathrm{ISO}+\mathrm{SO} 2)$, and sodium metabisulfite-treated (SO2). In order to induce hypertrophy in the model, we used $40 \mathrm{mg} / \mathrm{kg}$ of isoproterenol per day for 7 days by intraperitoneal injection and $40 \mathrm{mg} / \mathrm{kg}$ of sodium metabisulfite per day as an $\mathrm{SO}_{2}$ donor by means of gavage. Control group animals were given $0.9 \%$ saline solution. The animals were euthanized a day after the last injection in order to avoid the acute stimulant adrenergic effect of isoproterenol.

\section{Electrocardiography}

Rat ECG recordings were acquired under 2\% isoflurane anesthesia. Limb II ECGs were recorded continuously using subcutaneous needle electrodes connected to a Biopac MP100 amplifier. Isoelectric line drift due to respiration was eliminated by applying a $1 \mathrm{~Hz}$ high-pass filter to the recordings. 30 to 45 beats were selected from the noise-free signal and analyzed for QT interval and corrected QT (Qtc).

\section{Single ventricular cardiomyocyte isolations}

Rats were anesthetized with pentobarbital sodium (20 mg/ $\mathrm{kg}$ ) before rapid excision and the aorta was cannulated on a Langendorff system. Hearts were perfused with $\mathrm{Ca}^{2+}$-free solution [in mM: $145 \mathrm{NaCl}, 5 \mathrm{KCl}, 1.2 \mathrm{MgSO}_{4^{\prime}} 1.4 \mathrm{Na}_{2} \mathrm{HPO}_{4}, 0.4$ $\mathrm{NaH}_{2} \mathrm{PO}_{4}, 5$ HEPES, and 10 glucose ( $\mathrm{pH}$ adjusted to 7.4 with $\mathrm{NaOH}$, at $37^{\circ} \mathrm{C}$ )] for $3-4$ minutes to abduct remaining blood in coronary arteries. Afterwards they were perfused with the same solution containing $0.7-1 \mathrm{mg} / \mathrm{ml}$ collagenase (collagenase A, Roche) and $0.04-0.08 \mathrm{mg} / \mathrm{ml}$ protease (protease IV) for 20-25 minutes. In the following steps, the left ventricle was separated from the whole heart, minced into small pieces, triturated by Pasteur pipette, massaged through a nylon mesh, and dissociated cardiomyocytes were washed with the $\mathrm{Ca}^{2+}$-free solution. Later, the $\mathrm{Ca}^{2+}$ concentration of the cardiomyocyte suspension was gradually increased to 1.8 $\mathrm{mM}$. Calcium-tolerant cells were kept at room temperature and used for experiments on the same day.

\section{Electrophysiological parameters}

In this study, we studied action potential, voltage-dependent $\mathrm{Na}^{+}\left(I_{\mathrm{Na}}\right)$, transient outward $\mathrm{K}^{+}$ $\left(I_{\text {to }}\right)$, steady state $\mathrm{K}^{+}\left(I_{\text {ss }}\right)$, and L-type $\mathrm{Ca}^{2+}$ currents 
$\left(I_{\text {CaL }}\right)$ using a patch-clamp amplifier (Axon Axopatch 200B, Molecular Devices) in whole-cell configuration. During patch-clamp experiments, cells were studied within Tyrode solution [in mM: $137 \mathrm{NaCl}, 5.4 \mathrm{KCl}, 0.5 \mathrm{MgCl}_{2}, 1.5 \mathrm{CaCl}_{2}, 11.8 \mathrm{HEPES}$, and 10 glucose (pH adjusted to 7.4 with $\mathrm{NaOH}$, $37^{\circ} \mathrm{C}$ )] and pipette resistance was kept between 1.5-2.5 M $\Omega$ (P700 Puller, Sutter Instrument). The pipette solution used contained (in mM) 140 $\mathrm{KCl}, 5 \mathrm{NaCl}, 4 \mathrm{Na}_{2}$ ATP, $4.5 \mathrm{MgCl}_{2}, 10$ HEPES and $\mathrm{pH}$ was kept at 7.2 using $\mathrm{NaOH}$. Action potential was evoked by $4 \mathrm{~ms}$ square pulses at $1 \mathrm{~Hz}$. Action potential (AP) amplitude, time to peak, action potential duration (APD) at 50\% $\left(\mathrm{APD}_{50}\right)$ and $90 \%\left(\mathrm{APD}_{90}\right)$ of repolarization, and the resting membrane potential were calculated.

During the $I_{\mathrm{Na}}$ experiment, cells were kept in Tyrode solution and superperfused with external solution [in mM: $120 \mathrm{NaCl}, 10 \mathrm{TEA}, 5 \mathrm{CsCl}, 1 \mathrm{MgCl}_{2}$, 10 glucose, 10 HEPES, $1.5 \mathrm{CaCl}_{2}$, and $0.5 \mathrm{CdCl}_{2}$ ( $\mathrm{pH}=7.4$, adjusted with $\mathrm{CsOH})]$. The patch pipette was filled with internal solution containing (in mM) $120 \mathrm{CsCl}, 5 \mathrm{Na}-A T P, 5$ MgCl , 10 TEA, 10 HEPES, $1 \mathrm{CaCl}_{2}$, and $0.3 \mathrm{LiCl}(\mathrm{pH}=7.2$, adjusted with $\mathrm{CsOH})$. Cells were held at $-120 \mathrm{mV}$ and $I_{\mathrm{Na}}$ was obtained by voltage steps to potential ranging from -100 $\mathrm{mV}$ to $+40 \mathrm{mV}$ with $5 \mathrm{mV}$ increments. For steadystate inactivation, cells were held for 1 second at different potentials from $-140 \mathrm{mV}$ to $20 \mathrm{mV}$ with 5 $\mathrm{mV}$ additions before a step to $-40 \mathrm{mV}$ to elicit $I_{\mathrm{Na}}$. To study recovery from inactivation, cells were held at $-120 \mathrm{mV}$ and two $20 \mathrm{~ms}$ pulses to $-30 \mathrm{mV}$ were applied with $5 \mathrm{~ms}$ increment in the interval between pulses of consecutive episodes.

During $\mathrm{K}^{+}$current recording, the use of 250 $\mu \mathrm{M}$ cadmium chloride $\left(\mathrm{CdCl}_{2}\right)$ inhibits calcium current. For the measurement of $I_{\text {to }}$ and $I_{\text {ss' }}$ cells were held at $-70 \mathrm{mV}$ and a prepulse from $-70 \mathrm{mV}$ to $-45 \mathrm{mV}$ was used to inactivate voltage dependent $\mathrm{Na}^{+}$channels. Next, 1000 ms depolarizing voltage steps between -120 mV and $+70 \mathrm{mV}$ were performed. I $_{\text {to }}$ was measured as the difference between peak current and the last part of the current which was defined as sustained current.
For the measurement of $I_{\text {cal, }}$ cells in the Tyrode solution were superperfused with external solution (in mM: $137 \mathrm{NaCl}, 5.4 \mathrm{CsCl}, 1$ $\mathrm{MgCl}_{2}, 1.8 \mathrm{CaCl}_{2}, 5 \mathrm{HEPES}$ ). Patch pipettes were filled with a solution containing (in mM) 140 $\mathrm{CsCl}, 5 \mathrm{NaCl}, 4 \mathrm{Na}_{2}$ ATP, $4.5 \mathrm{MgCl}_{2}, 10$ EGTA, and 10 HEPES; this was kept at pH 7.2 using $\mathrm{CsOH}$. The voltage-clamp protocol consisted of a $100 \mathrm{~ms}$ prepulse from $-70 \mathrm{mV}$ to $-45 \mathrm{mV}$ to inactivate the sodium channels. Following this step, 300 ms depolarizing voltage steps were performed between $-50 \mathrm{mV}$ and $+50 \mathrm{mV}$. I caL was measured to differentiate between peak current and steady current at the end of the pulse. In order to calculate the inactivation kinetic of $I_{\text {CaL, }}$ two exponential equations (fast and slow) were fitted to the currents at $0 \mathrm{mV}$.

Intracellular $\mathrm{Ca}^{2+}$ transients were measured by means of a ratiometric fluorescence $\mathrm{Ca}^{2+}$ indicator; Fura-2AM (Invitrogen). In order to load the fluorescence dye, isolated single cells were incubated with $4 \mu \mathrm{mol} / \mathrm{L}$ Fura-2AM at $37{ }^{\circ} \mathrm{C}$ for 1 hour and then washed three times with fresh Tyrode solution. After a 1 hour de-esterification period, the cells were transferred under inverted microscope (Olympus IX71). Excitation wavelengths were 340 and $380 \mathrm{~nm}$, the emission was measured at $510 \mathrm{~nm}$ (IonOptix Inc.). The fluorescence ratio of the emitted light at 340 and $380 \mathrm{~nm}\left(\mathrm{~F}_{340 / 380}\right)$ was calculated as an indicator of $\left[\mathrm{Ca}^{2+}\right]_{i}$. Peak amplitude and time to $90 \%$ baseline were determined from $\mathrm{Ca}^{2+}$ transient responses evoked by field stimulation at $1 \mathrm{~Hz}$ frequency. Background fluorescence measured from the cell free field was subtracted from all recordings before calculation of the ratio.

\section{Mathematical AP modelling}

We optimized a detailed Hodgkin-Huxley type multi-compartment model by incorporating ion channels recorded experimentally from rat ventricular cardiomyocytes. All ion channels are modeled as described in Şengül et al. 2020. A stiff differential equation solver function was used 
with Gear's method ( $d t=0.01)$. For optimization, the modeling part of the code was rewritten in the $\mathrm{C}$ programming language to calibrate with experimental data. A nonlinear optimization library has been integrated to the code that includes a variety of optimization functions. Following the optimization step, conductance of related ion channels in the model were determined. The modeled action potential is generated with an applied current of $0.50 \mathrm{nA}$ for 5 seconds adapted from the experimental protocol used to evoke action potentials in rat ventricular myocytes.

\section{RESULTS}

\section{$\mathrm{SO}_{2}$ did not cease the isoproterenol-induced hypertrophy}

The mean heart weight to body weight (HW/BW) ratio of both the ISO and ISO+SO2 groups were increased compared to that of the control (Table I). The ISO+SO2 group had a mean HW/BW ratio that was statistically lower than that of the ISO group but was not entirely returned to that of the Control group. We were not able to determine the cardiac hypertrophic levels using the HW/
BW ratio because of the unequal loss in the BW of the rats in 7 days (Table I). Alternatively, we evaluated the heart weight to tibia length (HW/ $\mathrm{TL}$ ) ratio, which was not affected by changes in BW during the experimental period. The HW/ $T L$ ratio of the ISO group was increased, but it was not substantially different from that of the $\mathrm{ISO}+\mathrm{SO} 2$ group. Thus, $\mathrm{SO}_{2}$ alone did not make a difference in the $\mathrm{HW} / \mathrm{TL}$ of the ISO and ISO+SO2 groups and the control (Table I). The myocyte cell capacitance values were measured during the whole cell voltage clamp procedure also which gave information about the hypertrophic state of the heart, beside the global hypertrophic indices. The mean capacitance values of the groups were also verified the HW/TL results.

\section{QT interval was reformed by $\mathrm{SO}_{2}$ administration.}

In order to determine $\mathrm{SO}_{2}$ effect on excitation of the hypertrophic heart, limb II derivation of ECG was recorded from the rats of experimental groups and the results were given in Figure $1 \mathrm{a}$. After 7 days of isoproterenol administration, the heart rates of the ISO group animals were increased compared to those of the Control

Table I. Morphological parameters of animals.

\begin{tabular}{|c|c|c|c|c|}
\hline Experimental Group & $\begin{array}{l}\text { Control } \\
(n=30)\end{array}$ & $\begin{array}{c}\text { ISO } \\
(n=24)\end{array}$ & $\begin{array}{c}\text { ISO+SO2 } \\
(n=26)\end{array}$ & $\begin{array}{c}\text { SO2 } \\
(n=26)\end{array}$ \\
\hline Initial BW & $312.3 \pm 8.4$ & $338.6 \pm 11.4$ & $320.0 \pm 8.5$ & $315.0 \pm 11.2$ \\
\hline Final BW & $324.2 \pm 8.7$ & $298.3 \pm 6.7$ & $301.9 \pm 8.9$ & $324.5 \pm 10.8$ \\
\hline \% BW Change & $3.9 \pm 0.5$ & $(-) 5.2 \pm 0.8$ & $(-) 2.3 \pm 1.3$ & $3.3 \pm 0.6$ \\
\hline HW (g) & $1.34 \pm 0.03$ & $1.73 \pm 0.05$ & $1.67 \pm 0.04$ & $1.33 \pm 0.05$ \\
\hline $\mathrm{TL}(\mathrm{cm})$ & $3.91 \pm 0.02$ & $3.86 \pm 0.04$ & $3.84 \pm 0.03$ & $3.84 \pm 0.04$ \\
\hline HW/BW ( $\mu \mathrm{g} / \mathrm{g})$ & $4.15 \pm 0.07$ & $5.88 \pm 0.13^{*}$ & $5.58 \pm 0.08^{\star} \#$ & $4.10 \pm 0.06$ \\
\hline HW/TL (mg/m) & $34.31 \pm 0.65$ & $45.23 \pm 1.08^{*}$ & $44.31 \pm 0.92^{*}$ & $34.91 \pm 1.03$ \\
\hline $\mathrm{Cm}(\mathrm{pF})$ & $268 \pm 9.86$ & $343 \pm 12.7^{\star}$ & $365 \pm 17.6^{*}$ & $275 \pm 13.79$ \\
\hline
\end{tabular}

Values are means \pm SEM. ${ }^{*} p<0.01$ versus Control animals; \#p<0.01 versus ISO animals. HW: Heart Weight, BW: Body Weight, TL: Tibia Length.

$\mathrm{Cm}$ :Cell membrane capacitance. 
group. On the other hand, the heart rates of ISO+SO2 animals were not statistically significant compared to those of the Control group and significantly decreased compared to the ISO group (Figure 1b). In contrast to the unchanged QRS amplitude in the groups (Figure 1c), the QT interval of the ISO group was significantly prolonged compared to that of the Control group (Figure 1d).

Interestingly, recovery of $\mathrm{SO}_{2}$ levels in ISO group animals shortened the prolonged QT interval in ISO+SO2 group animals as shown in figure 1d. Additionally, QTC was calculated using Bazett's approach to prevent ventricular repolarization from heart rate variability. QTC values were presented in figure 1e. Based on these data, it was found that ventricular repolarization was prolonged in the ISO group compared to the Control group. Furthermore, this prolongation decreased in the $\mathrm{ISO}+\mathrm{SO} 2$ group as well.

\section{$\mathrm{SO}_{2}$ blocked the action potential prolongation}

The action potentials that we recorded helped us to identify the course of action on the excitation of the single ventricular cardiomyocytes. Initially, the peak periods of the action potentials were not significantly different among the experimental groups (Figure $2 b$ ). We were able to evaluate the difference in amplitudes only with the $\mathrm{ISO}+\mathrm{SO} 2$ group. Nonetheless, the action potentials of the $\mathrm{ISO}+\mathrm{SO} 2$ group had larger amplitudes compared to those of the ISO and the Control groups (Figure 2e). Thus, the major determinant of cardiomyocyte excitability may be the resting membrane potential (RMP), and the modification of this phenomenon may impair several physiological processes. The average RMP of the ISO+SO2 group was lower than that of the control. Nevertheless, the ISO+SO2 group was more hyperpolarized than the ISO group and the Control (Figure 2f). The most applicable parameter turned out to be APD, considering that stable excitation particularly during the APD is required for healthy contraction. Half width durations $\left(\mathrm{APD}_{50}\right)$ of the cardiomyocytes did not differ significantly between the experimental groups, although the isoproterenol applied groups' (ISO and ISO+SO2) APD 50 values were slightly longer than that of the Control group (Figure 2c). In addition, the ventricular myocytes of both the ISO and ISO+SO2 groups had longer $A P D_{90}$ parameters compared to those of the control. Moreover, $\mathrm{SO}_{2}$ application markedly shortened the $\mathrm{APD}_{90}$ of the ISO+SO2 group, but it did not affect the $\mathrm{APD}_{90}$ of the $\mathrm{SO} 2$ group (Figure 2d).

\section{$\mathrm{SO}_{2}$ did not modify $I_{\mathrm{Na}}$ in isoproterenol induced hypertrophic heart}

The $I_{\mathrm{Na}}$ in ventricular cardiomyocytes is the basic current for excitation processes, considering that it triggers the fast upstroke of the action potential. Previous studies have even demonstrated the forward potency of $I_{\mathrm{Na}}$ on the repolarization phase of action potential. The voltage characteristics of the $I_{\mathrm{Na}}$ density in the ISO and ISO+SO2 groups is considerably decreased compared to those of the control (Figure $3 \mathrm{~b}$ ). Conversely, the $I_{\mathrm{Na}}$ density in the ventricular myocytes of the $\mathrm{SO} 2$ group was increased relative to that of the control. Nonetheless, there were no differences in the I-V characteristics of the $I_{\mathrm{Na}}$ density between ISO and $\mathrm{ISO}+\mathrm{SO} 2$ groups as seen in figure 3b. These results indicate that $I_{\mathrm{Na}}$ does not play a role in the mechanism of action potential shortening as a result of $\mathrm{SO}_{2}$ administration.

\section{I-V characteristics of the $\mathrm{K}^{+}$currents failed to explain the $A P D_{90}$ alteration}

The voltage-gated $\mathrm{K}^{+}$channels are the primary determinants of action potential repolarization in the mammalian myocardium. Being in the early stage of repolarization in ventricular cells, 

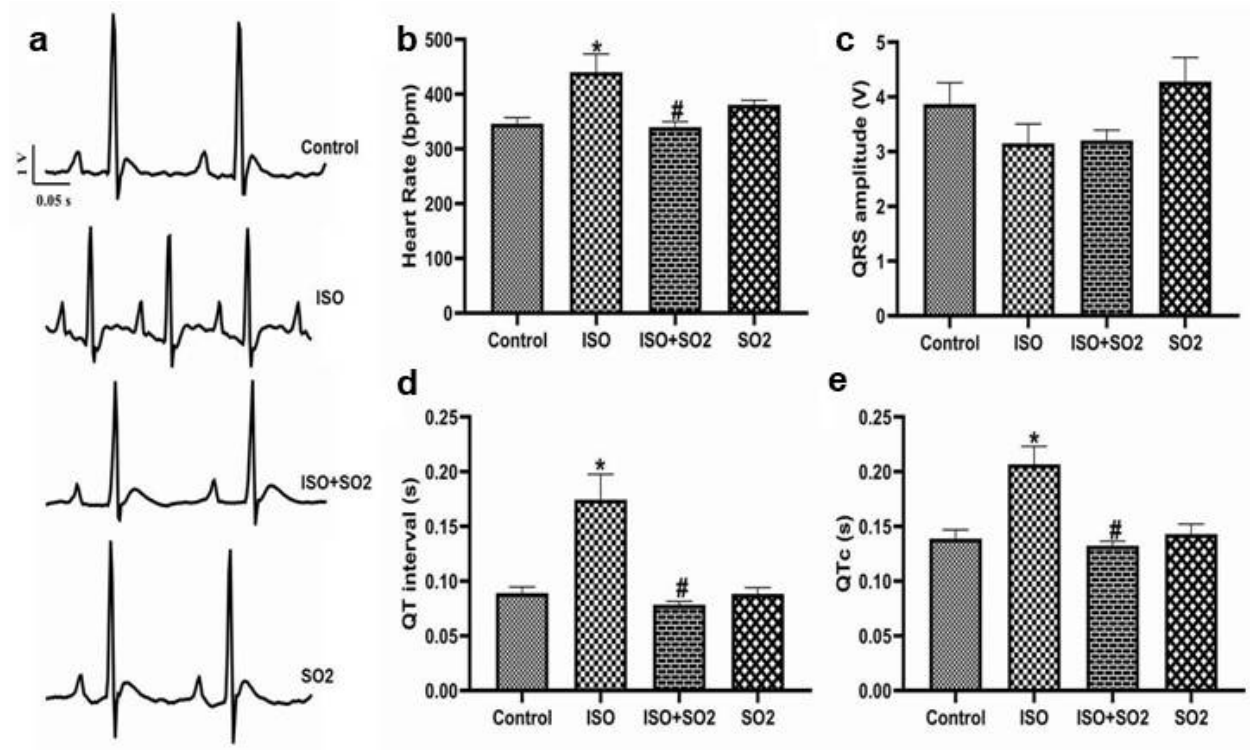

Figure 1. ECG characteristics of experimental groups. Representative ECG signals of heart recorded from each experimental groups (a). Heart rate (b) was elevated in ISO compare to control groups, while ISO+SO2 was lowered to control levels. QRS amplitude (c) was not changed between groups. QT interval (d) demonstrated that ventricular repolarization time was elevated in ISO compare to control group, also reduced in ISO+SO2 compare to ISO group. The QTc (e) parameter also shows same pattern of QT changes. Values are means \pm SEM. * $p<0.01$ versus Control; \#p<0.01 versus ISO.
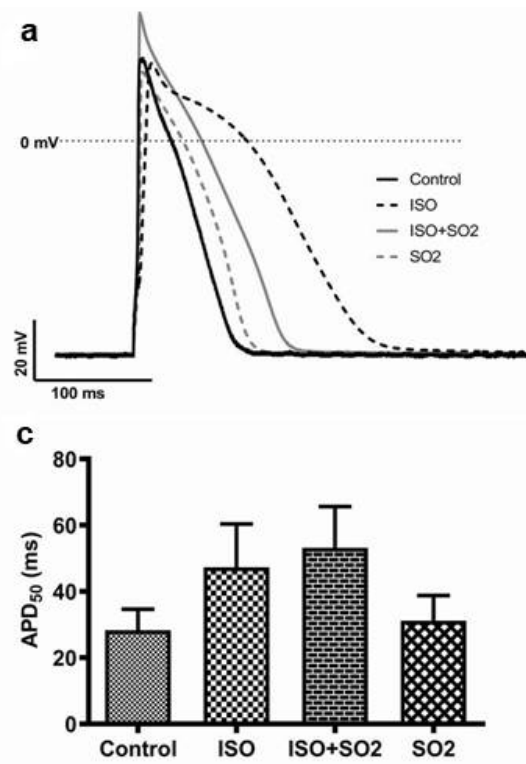

e

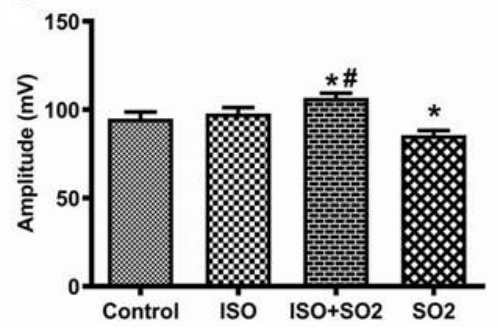

b

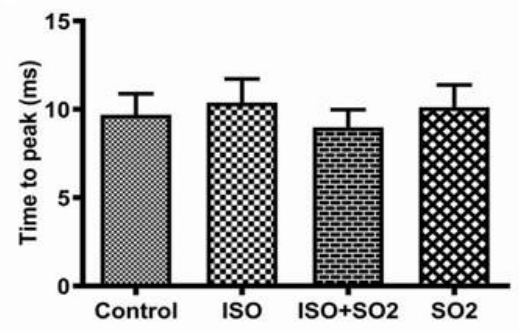

d

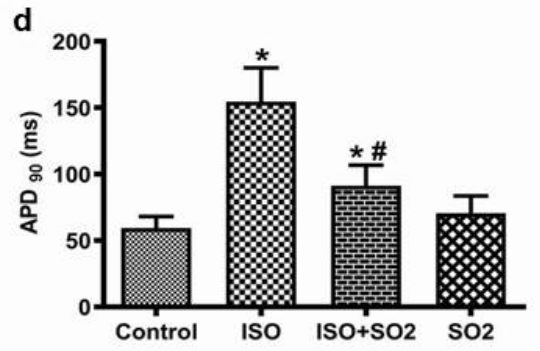

f

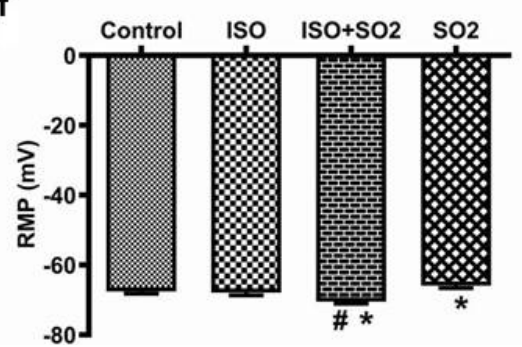

Figure 2. Action potential properties of cardiomyocytes. Representative action potentials of left ventricular single cardiomyocytes recorded from each experimental groups (a). The action potential time to peak (b) was not changed between groups. Although APD ${ }_{50}$ values $(c)$ increased in ISO and ISO+SO2 group with respect to Control group, they were not statistically significant. $A D_{90}$ values (d) increased by isoproterenol application significantly decreased with $\mathrm{SO}_{2}$ supplementation. ISO+SO2 group animals have increased AP amplitude (e) and RMP (f). $\mathrm{APD}_{50}$ or $\mathrm{APD}_{90}$ : Action Potential Duration at $50 \%$ or $90 \%$ repolarization. RMP: Resting Membrane Potential. Values are means \pm SEM. * $p<0.01$ versus Control; \#p<0.01 versus ISO (Number of cells; Control:18, ISO:16, ISO+SO2:18, SO2:16). 
a
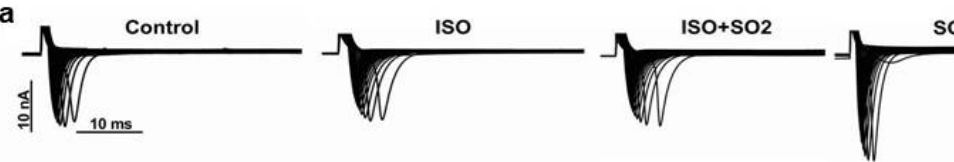

so2

Membrane Potential (mV)

b

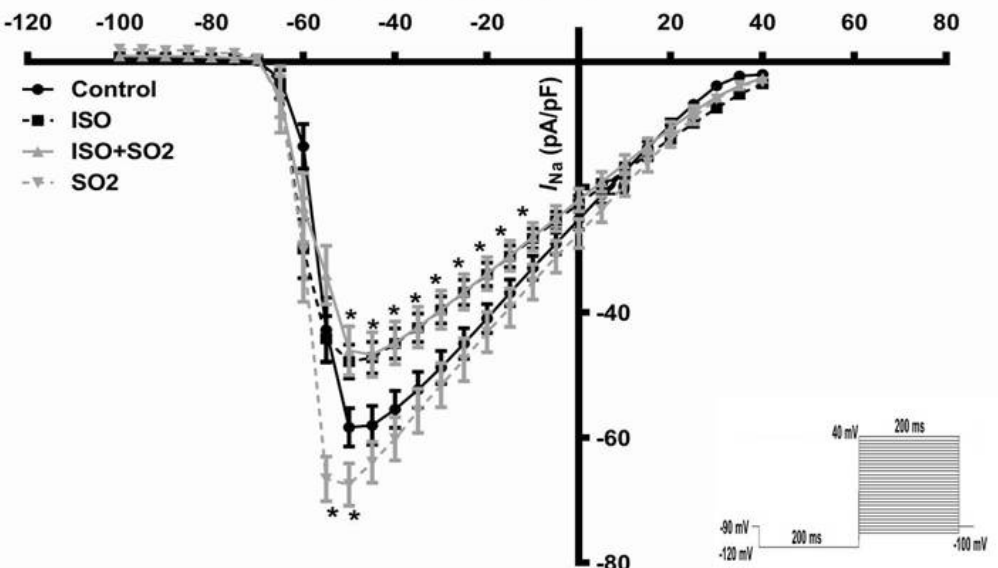

c
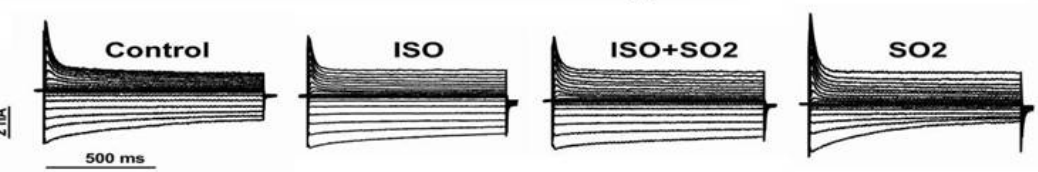

d

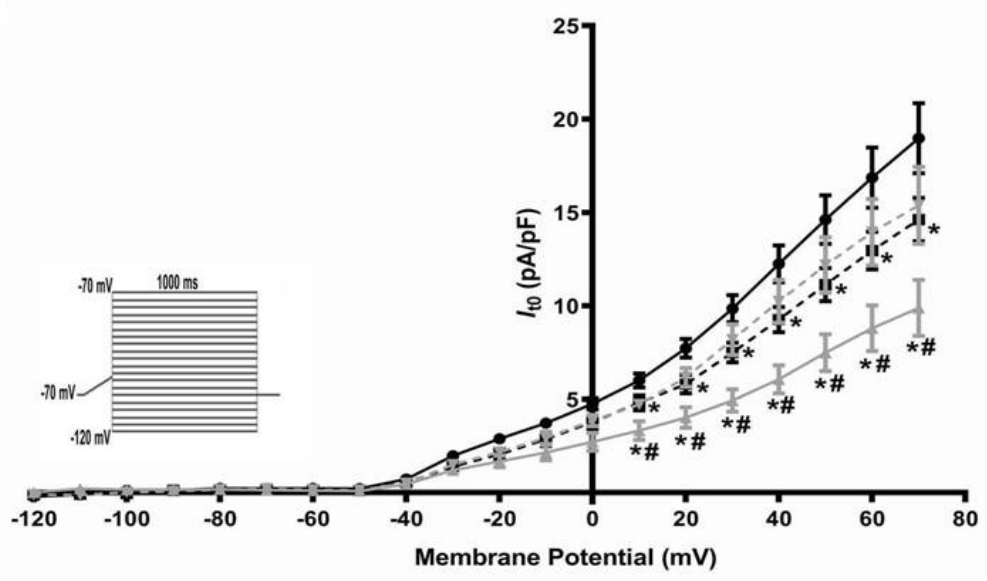

e

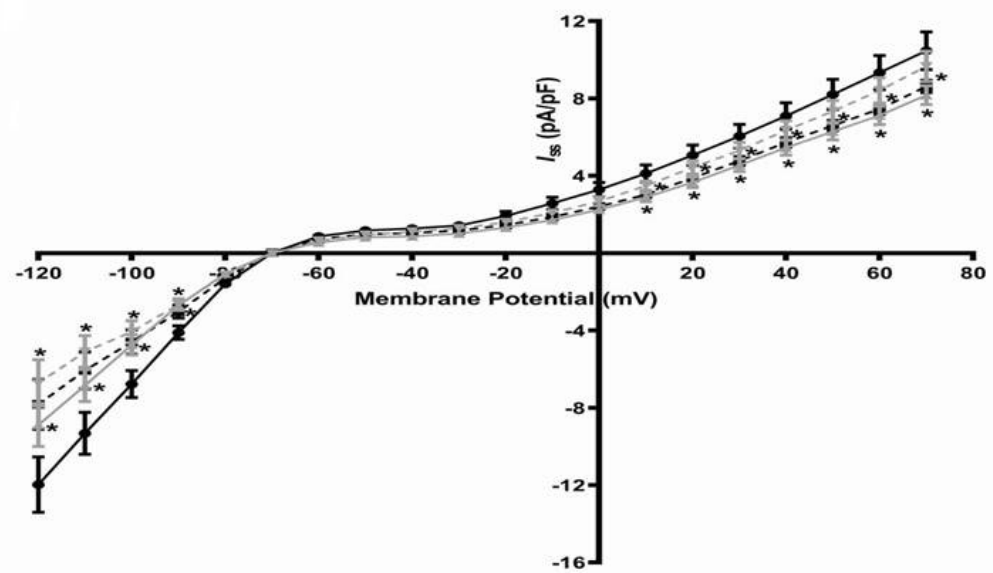

Figure 3. Current-voltage characteristics of $I_{\mathrm{Na}}$ and voltage characteristics of $I_{\mathrm{to}}, I_{\mathrm{ss}}$ and $I_{\mathrm{k} 1}$. The representative $I_{\mathrm{Na}}$ traces of experimental groups was showned in panel (a). The density of $I_{\mathrm{Na}}$ (b) was decreased by isoproterenol. Values are means \pm SEM. * $p<0.01$ versus Control (Number of cells; Control:24, ISO:31, ISO+SO2:22, S02:14). The representative $I_{K}$ traces of experimental groups was shown in panel (c). The $I_{\text {to }}$ density (d) of ISO and $\mathrm{ISO}+\mathrm{SO} 2$ was reduced compared to control group. Also, the values of ISO+SO2 were decreased compare to ISO group between the voltages of $+10 \mathrm{mV}$ and $+70 \mathrm{mV}$. Voltage characteristics of the steady state currents (e) of isoproterenol applied groups were increased with respect to control group. Also, the voltage characteristics of $I_{K 1}$ was reduced experimental groups compare to control group and did not reveal any explanatory information about the shortening effect of $\mathrm{SO}_{2}$. Values are means \pm SEM. ${ }^{*} p<0.01$ versus Control; $\# p<0.01$ versus ISO (Number of cells; Control:22, ISO:11, ISO+SO2:11, SO2:11). 
$I_{\text {to }}$ currents are rapidly activated and inactivated at positive membrane potentials of more than -30 $\mathrm{mV}$. The results of the voltage clamp experiment on I-V characteristics show that the $I_{\text {to }}$ was significantly reduced in hypertrophic animals (ISO and ISO+SO2). In addition, the $I_{\text {to }}$ density of ISO+SO2 was further decreased as compared to that of the ISO group (Figure 3d). Remarkably, the decrease of the $I_{\text {to }}$ density in the ISO+SO2 group was more pronounced at all membrane potentials. Nonetheless, these findings that are deduced from I-V characteristics do not endorse the prolongation of action potential in the hypertrophic model, not even the shortening mechanism of $\mathrm{SO} 2$ on the action potential.

The steady-state background currents are efficient modulators of the action potential plateau in ventricular myocytes. These currents contain several components such as the $I_{\mathrm{K} 1}$, the delayed $\mathrm{K}^{+}$current, and the background $\mathrm{K}^{+}$current. In our experiments, the whole-cell current elicited by the voltage ramps in the ventricular cells of all the groups revealed the possible role of the currents in the prolongation of the repolarization phase of the action potentials of both the ISO and ISO+SO2 groups, since the $I_{\text {ss }}$ in both the ISO and ISO+SO2 groups was significantly decreased relative to that of the control. However, the $I_{\text {ss }}$ densities were not considerably different among all the groups (Figure 3e). $I_{\mathrm{k} 1 \text {, }}$ a determining current of the repolarization phase in cardiomyocytes, can be deduced from the potential between -70 and -120 mV from I-V characteristic curves (Figure 3e). The $I_{\mathrm{K} 1}$ density of all experimental groups was decreased when compared to that of the control group.

\section{$\mathrm{SO}_{2}$ hindered the isoproterenol-induced reduction of $I_{\mathrm{CaL}}$ and $\left[\mathrm{Ca}^{2+}\right]_{\mathrm{i}}$}

Calcium ion currents in cardiomyocytes are crucial to explain excitation and contraction alterations in cardiomyocytes. In order to understand the underlying mechanisms of extended $\mathrm{APD}_{90}$, we have investigated $I_{\text {cal }}$ in freshly isolated cardiomyocytes. The $I_{\text {cal }}$ density in the ISO group was significantly decreased, whereas that of the $\mathrm{ISO}+\mathrm{SO} 2$ group was remarkably increased and returned to the level of the Control group (Figure 4c). Activation and inactivation kinetics of voltage control channels determine the current during action potentials. We found that isoproterenol administration lowers the fast inactivation constant (Tf) at 0 $\mathrm{mV}$ compared to the Control group (Figure 4e). However, the ISO+SO2 group had an elevated slow inactivation constant (TS) at $0 \mathrm{mV}$ compared to the ISO groups (Figure 4f). Additionally, SO2 administration had a speeded up tf at $0 \mathrm{mV}$ compared to the Control groups (Figure $4 \mathrm{e}$ ). While a slowdown in Ts at $0 \mathrm{mV}$ was observed in the ISO group compared to the Control group (Figure 4f).

Although there was an increase in isoproterenol administration in terms of calcium discharged from SR, no significant difference was observed between the control groups. At the same time, The ISO+SO2 groups had an increase in $\Delta \mathrm{F}_{340 / 380}$ compared to not only the Control but also the ISO groups. Furthermore, SO2 administration had enhanced $\Delta F_{340 / 380}$ compared to the Control group (Figure $4 \mathrm{~g}$ ). In terms of calcium removal from intracellular space, a decrease was observed in the $\mathrm{ISO}+\mathrm{SO} 2$ group compared to the Control and ISO groups. In addition, SO2 administration also had a decreased time to baseline of $90 \%$ compared to the Control group. There was no statistically significant difference between the ISO and Control groups in terms of time to baseline $90 \%$ (Figure 4h). 
The mathematical model clarified electrophysiological results

Alteration in the action potential duration of cardiomyocytes may not be adequately interpreted as linear interaction of transmembrane ion currents estimated from the I-V relationship. The nonlinear interaction between membrane ion channels, transmembrane voltage and dynamically changing ionic concentrations must be considered. Hence, the mathematical model of the ventricular cardiomyocytes action potential was used to complete the interpretation of the focused results. The amplitudes and APDs of the modeled groups were parallel with those of all respective experimental groups (Figure 5). The changes in the AP duration and underlying ionic currents were observed in both the hypertrophic heart and $\mathrm{SO}_{2}$ application that can be examined a

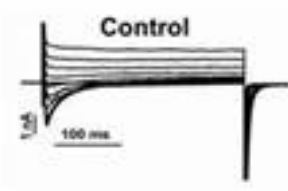

b
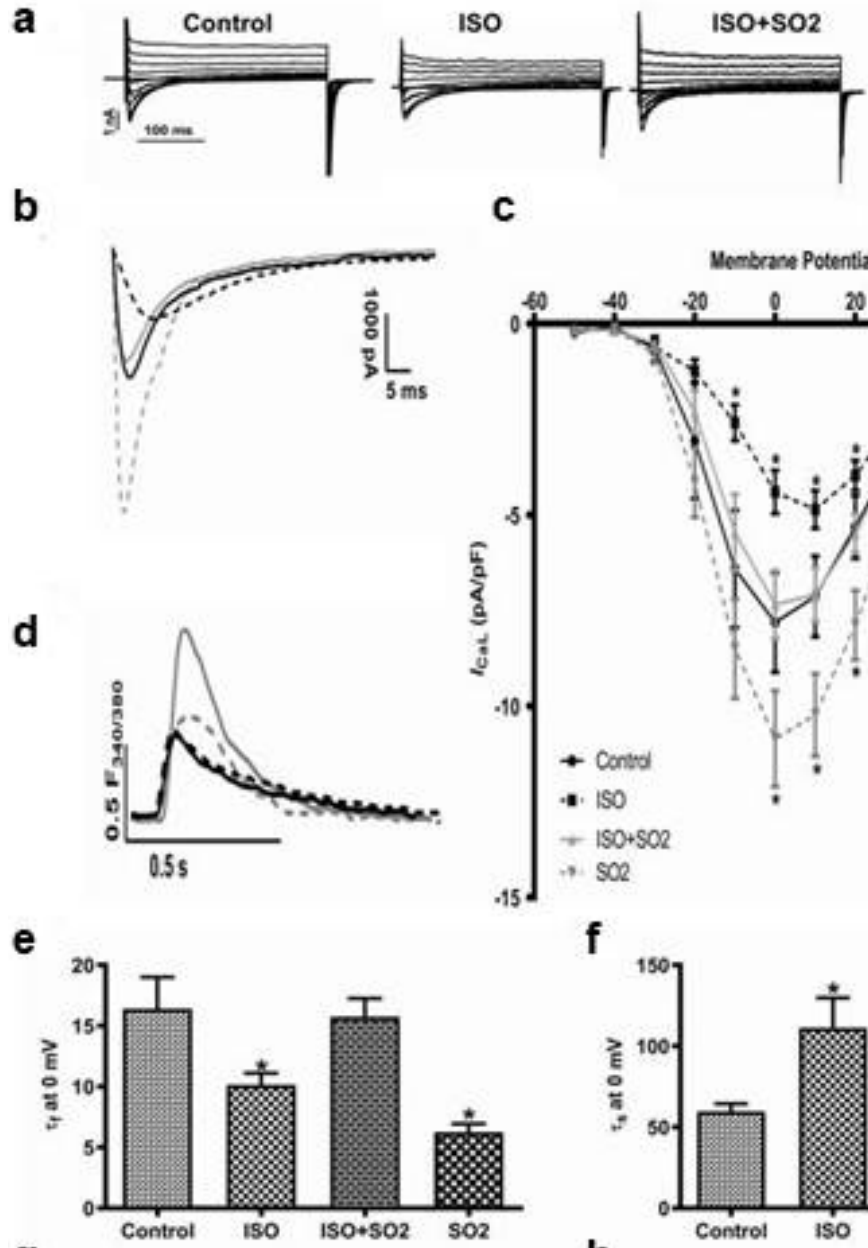

g
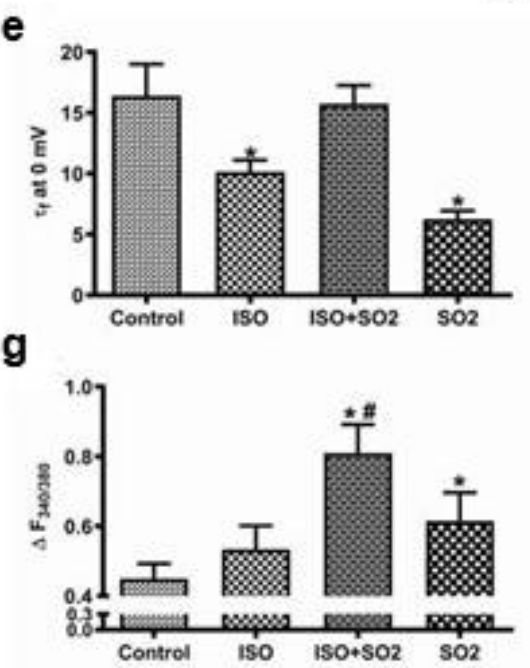

c

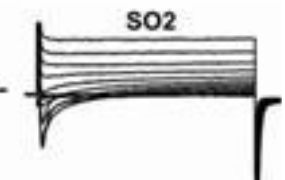

1
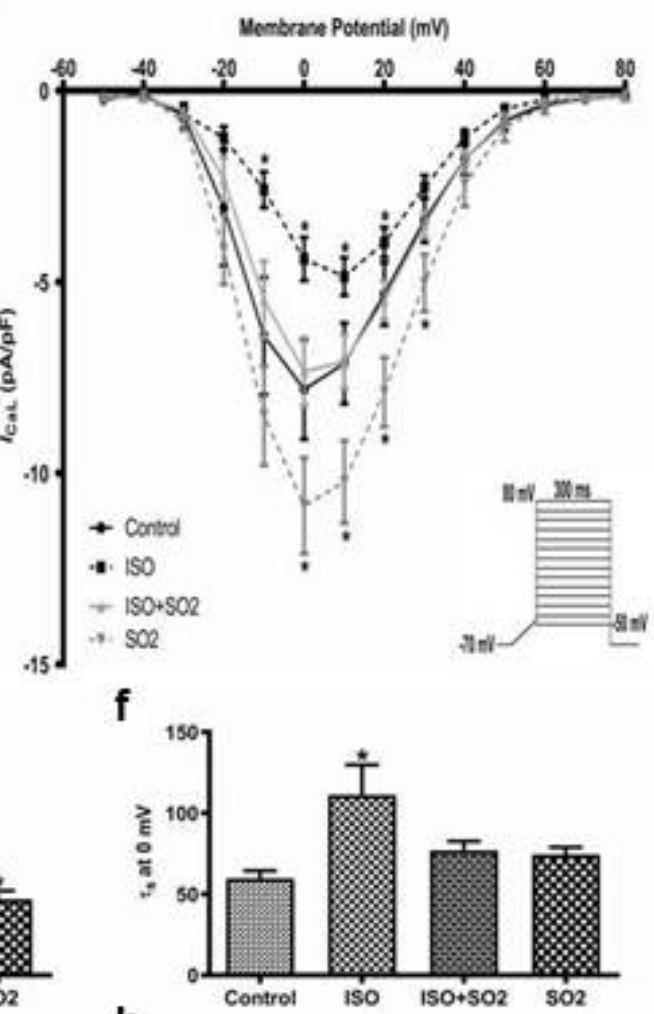

h

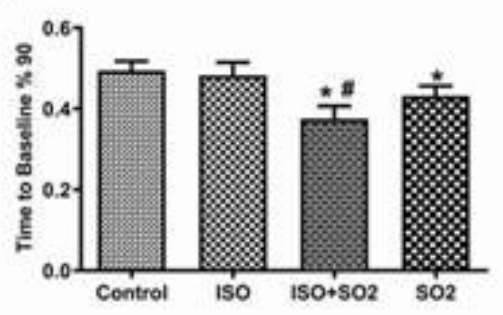

Figure 4. Current-voltage characteristics of $I_{\mathrm{cat}}$. Representative total $\mathrm{Ca}^{2+}$ current signals at all clamped potentials (a) and I-V characteristics of $I_{\text {cat }}$ (c) recorded from each experimental groups. $I_{\text {cat }}$ density were reduced by isoproterenol application. However, $I_{\text {cal }}$ density of $\mathrm{ISO}+\mathrm{SO} 2$ was reversed to the control level. Additionally, the $I_{\text {cat }}$ of SO2 was augmented compared to the control group. Representative comparison of $I_{\text {Cat }}$ kinetics at $0 \mathrm{mV}$ can be seen in panel (b). Inactivation of $I_{\text {cat }}$ were calculated by fitting two exponential, defined as slow and fast inactivation (e and f, respectively). While isoproterenol administration impaired fast and slow inactivation kinetics, values of ISO+SO2 were reversed to control values by $\mathrm{SO}_{2}$ administration. However $\mathrm{SO}_{2}$ accelerated fast kinetic compare to the control group. Representative total $\mathrm{Ca}^{2+}$ transient signals was showed in panel (d). $\Delta \mathrm{F}_{340 / 380}$ demonstrate peak discharged of $\mathrm{Ca}^{2+}$ from SR (g). Transients height was elevated in ISO+SO2 compare to control and ISO groups. While $\mathrm{Ca}^{2+}$ reuptake time $(\mathrm{h})$ into $\mathrm{SR}$ were accelerated in ISO+SO2. Values are means \pm SEM. ${ }^{*} p<0.01$ versus Control; $\# p<0.01$ versus ISO (Number of cells; Control:14, ISO:23, ISO+SO2:16, SO2:15). 
in the Supplementary Material Figures S1-S4 and Table SI.

\section{DISCUSSION}

Recent studies have proposed that endogenous $\mathrm{SO}_{2}$ has a role in the physiological and pathological mechanisms of the cardiovascular system, but their findings provide contradictory evidence, confounding the existing research. Nonetheless, these studies have at least paved the way for endogenous $\mathrm{SO}_{2}$ to be considered as a gasotransmitter.

One of the reasons for the contradictory results might arise from the presence of various sulfur-containing molecules. $\mathrm{SO}_{2}$ may exist in the gaseous form or may be hydrated to sulfite. Then it is subsequently oxidized by sulfite oxidase to sulfate, which is excreted in the urine (Stipanuk 1986, Singer \& Kearney 1956). Compared to $\mathrm{SO}_{2}$ derivatives, gaseous $\mathrm{SO}_{2}$ was claimed to be a more active molecule (Zhang \& Meng 2012). Furthermore, $\mathrm{SO}_{2}$ interacts with other gasotransmitters. In fact, $\mathrm{SO}_{2}$ and $\mathrm{H}_{2} \mathrm{~S}$ share the same endogenous substrate, L-cysteine, and they can mutually transform under certain biochemical conditions (Shapiro 1977, Kamoun
2004, Chen et al. 2011). They also have similar regulatory roles including vasorelaxation, antioxidative action, and inhibition of inflammation and apoptosis. Several studies indicate that the endogenous $\mathrm{SO}_{2}$ content of the heart may decrease significantly via the inhibiting glutamic oxaloacetic transaminase pathway in animal models of isoproterenolinduced myocardial injury (Liang et al. 2011), and that the administration of $\mathrm{SO}_{2}$ donor may restore the content (Chen et al. 2011).

The principal result of the study demonstrates that sodium metabisulfite as an $\mathrm{SO}_{2}$ donor prevents electrophysiological alteration in the isoproterenol-induced hypertrophic rat model. The prolongation of action potential is common in human heart failure and in animal models of cardiac hypertrophy, but remarkably, our study demonstrated that this could be prevented by $\mathrm{SO}_{2}$ administration (Figure $2 \mathrm{~d}$ ). Parallel to the prolongation, the QT and QTC interval, which indicates the repolarization period of the heart, also increased (Figure 1d, e). Therewithal, $\mathrm{SO}_{2}$ application reversed the QT and QTC interval to its normal value. Altogether, the shortening of action potential and the maintenance of

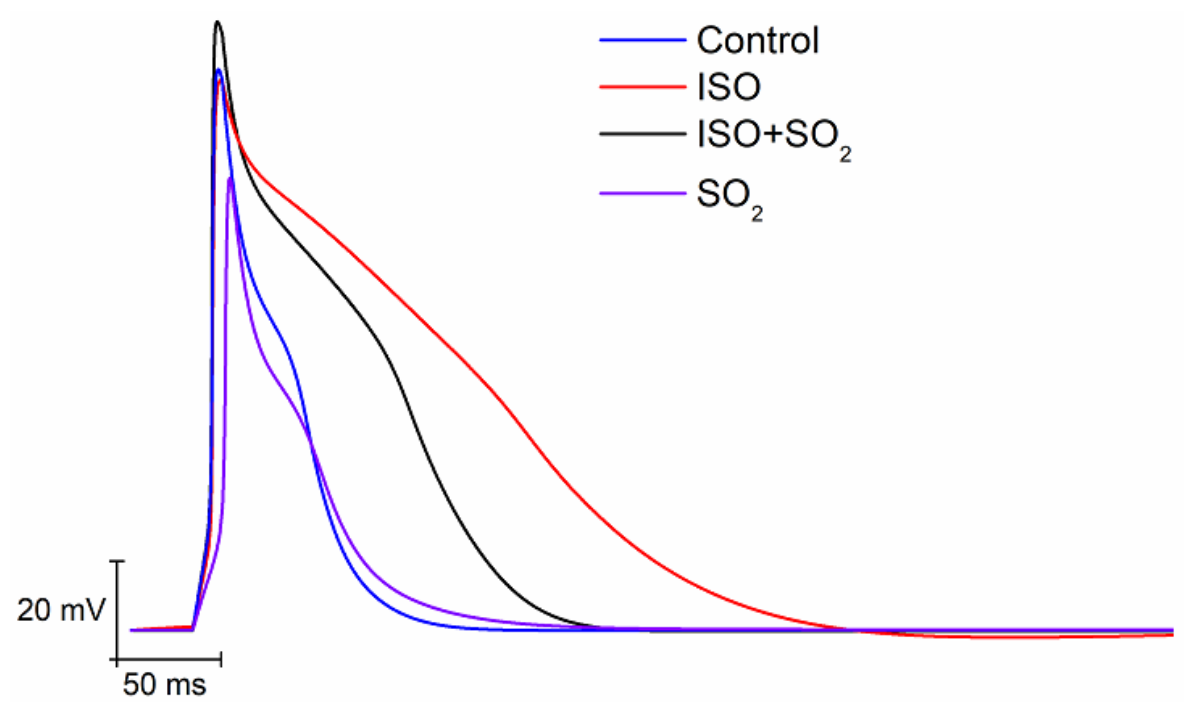

\author{
Figure 5. Ventricular action \\ potentials of respective \\ experimental groups were \\ calculated by a mathematical \\ model using equations from \\ Şengül et al. 2020. Calculated \\ action potentials corroborate \\ the results obtained \\ from electrophysiological \\ experiments. Please see \\ the Supplementary Material \\ Figures S1-S4 and Table SI for \\ detailed results of the ionic \\ currents and parameters.
}


the resting membrane potential due to $\mathrm{SO}_{2}$ suggest that the endogenous compound has an essential role in heart disorders such as long QT syndrome (LQTS) and arrhythmia.

The mechanism of action potential prolongation involves altered dynamics or expression of a variety of inward and outward currents in cardiomyocytes. Several studies have discussed the influences of endogenous or exogenous $\mathrm{SO}_{2}$ on the ionic currents that contribute to cardiomyocyte action potential dynamics (Zhang et al. 2011, Liu et al. 2010). Although the several reports about the effects of $\mathrm{SO}_{2}$ on most ionic currents of ventricular cardiomyocytes, we could not find one that is comparable to our findings, since they are motivated to reveal the direct effects of $\mathrm{SO}_{2}$ on physiological conditions. On the other hand, we used a pathophysiological condition in which the endogenous $\mathrm{SO}_{2}$ level is decreased. The principal inward current which set the action potential depolarization in motion is $I_{\mathrm{Na}}$. The density of $I_{\mathrm{Na}}$ in the cardiomyocytes of the isoproterenol-treated groups decreased at all clamped potentials (Figure 3b). With this result, we cannot explain either the prolongation of action potential in the ISO group or the reversal of APD to normal levels in the ISO+SO2 group. The $I_{\mathrm{Na}}$ does not directly affect APD, but it was suggested that the late $I_{\mathrm{Na}}\left(I_{\mathrm{NaL}}\right)$ may alter the repolarization phase (Guo et al. 2010). Nevertheless, our findings do not support this phenomenon in isoproterenol induced hypertrophy (data not shown).

Of all the mechanisms that may contribute to action potential prolongation, the decreased $I_{K}$ appears to be the most reported mechanism. Regardless of the species, precipitating factors, or the severity of hypertrophy, the decreased density of $I_{\text {to }}$ apparently plays a prominent role. It is apparent that altered $I_{\text {to }}$ density is the underlying cause of AP prolongation in the ISO group. However, I to density further decreased in the $\mathrm{ISO}+\mathrm{SO} 2$ group (Figure $3 \mathrm{~d}$ ), negating the effect of $\mathrm{SO}_{2}$ on action potential shortening in cardiac hypertrophy. Our findings on the I-V characteristics of $I_{\mathrm{K}}$ do not directly describe action potential shortening by $\mathrm{SO}_{2}$ donor application.

There have been extensive studies on the role of the $I_{\text {cal }}$ in the depolarization of the cardiomyocyte membrane through the inward current in human and animal models. On the other hand, the $\left[\mathrm{Ca}^{2+}\right]_{i}$ can act on a variety of signaling pathways, which affect $I_{\text {caL }}$ and other ionic currents. The I-V relationship of I cat failed to support prolongation or shortening of the action potential because the decreased $I_{\text {cal }}$ should cause the membrane to repolarize faster in the ISO group or restitution of it should prolong APD in the ISO+SO2 group. The activity of $I_{\text {Cal }}$ is associated with APD and it is suggested that it is controlled by voltage- and calcium-dependent inactivation (Faber et al. 2007, Morales et al. 2019). $\mathrm{Ca}^{2+}$ entry via the L-type calcium channel during action potential is greatly determined by its kinetic control by both voltage- and calciumdependent inactivation. Although different channels are effective in AP prolongation in hypertrophic ventricular cardiomyocytes, the mechanism of AP shortening appears to be due to the recovery of $\mathrm{Ca}^{2+}$-dependent inactivation of the L-type $\mathrm{Ca}^{2+}$ channels. The improvement of impaired $I_{\text {cal }}$ density and $\mathrm{Ca}^{2+}$ transients with $\mathrm{SO}_{2}$ administration in the hypertrophic model confirms this phenomena (Figure $4 \mathrm{C}, \mathrm{g}$ ), despite the contrariwise results in $I_{K}$ density.

The voltage-dependent properties of the related ionic currents were insufficient to describe the $\mathrm{SO}_{2}$ effect on cardiomyocyte electrophysiology. Thus, the action potential modeling of the cardiomyocytes provides a holistic perspective and an invaluable description of the coherence of our results with the prolongation and temporal shortening 
of the action potential in the experimental groups (Figures S1, S2, S3, S4 and Table SI). We successfully simulate the AP recorded in each experimental group calculated from the measured current densities and kinetics (Figure 5).

Notably, our mathematical modeling of the ionic currents resulted in discovering the improved kinetics of $I_{\text {caL }}$ and $I_{\text {ss }}$. Nevertheless, the increased density of $I_{\text {caL }}$ may not explain the reduction in the effects of $\mathrm{SO}_{2}$ on APD because $I_{\text {cal }}$ is an inward cation current that is supposed to prolong the action potential. However, increased $I_{\text {cal }}$ density along with improved $\mathrm{Ca}^{2+}$ transients can cause faster closure of the channel and a shorter duration of $I_{\text {cal }}$ during the course of an action potential via the $\mathrm{Ca}^{2+}$ dependent inactivation of the channels. Additionally, restitution of $I_{\mathrm{K} 1}$ by $\mathrm{SO}_{2}$ administration helps $I_{\text {cal }}$ to reduce APD in isoproterenol induced hypertrophic heart. The other candidate would be $I_{\text {ss' }}$ but the $I_{\text {to }}$ density significantly decreased and the $I_{\text {sS }}$ density lacked change in the ISO+SO2 group. The increased $I_{\text {cal }}$ density may indirectly shorten the APD by improving the $\mathrm{Ca}^{2+}$-dependent $\mathrm{K}^{+}$currents according to the simultaneous recovery of the $I_{\text {cal }}$ kinetics and the charge of the $I_{\text {ss }}$ during action potential in our simulation results (Figure S3). This issue does not alter our voltage clamp results because we used EGTA in the internal solution which blocked the intracellular $\mathrm{Ca}^{2+}$ elevation during the $\mathrm{K}^{+}$current measurement. Thus, we could not see a significant increase in the measured $l_{\text {ss }}$.

Although we were not able to observe the structural effects of $\mathrm{SO}_{2}$ in pathological conditions, we conclude that $\mathrm{SO}_{2}$ and its derivatives may significantly impact cardiomyocyte electrophysiology in the isoproterenol-induced hypertrophic heart. Our findings also support the potential role of endogenous $\mathrm{SO}_{2}$ metabolism in the isoproterenol-induced pathophysiology of ECC. This role should be further inspected to uncover the relationship between $\mathrm{SO}_{2}$ metabolism and cardiomyopathy.

\section{Acknowledgments}

This study was supported in part by Akdeniz University Scientific Research Coordination Unit (Project No: 2012.02.0122.009) and The Scientific and Technological Research Council of Turkey (TUBITAK, Project No: 117F020). These funding sources had no involvement in study design, writing of the report, decision to publish, or the collection, analysis, and interpretation of data.

\section{REFERENCES}

BERS DM. 2002. Cardiac excitation-contraction coupling. Nature 415: 198-205.

CHEN S, DU J, LIANG Y, OCHS T, LIU D, ZHU L, TANG X, TANG C \& JIN H. 2012a. Sulfur dioxide inhibits excessively activated endoplasmic reticulum stress in rats with myocardial injury. Heart Vessels 27: 505-516.

CHEN S, DU J, LIANG Y, ZHANG R, TANG C \& JIN H. 2012b. Sulfur dioxide restores calcium homeostasis disturbance in rat with isoproterenol-induced myocardial injury. Histol Histopathol 27: 1219-1226.

CHEN SY, JIN HF, SUN Y, TIAN Y, TANG CS \& DU JB. 2011. Impact of sulfur dioxide on hydrogen sulfide/ cystathionine-gamma-lyase and hydrogen sulfide/ mercaptopyruvatesulfurtransferase pathways in the pathogenesis of hypoxic pulmonary hypertension in rats. Zhonghua Er Ke Za Zhi 49: 890-894.

DU SX, JIN HF, BU DF, ZHAO X, GENG B, TANG CS \& DU JB. 2008. Endogenously generated sulfur dioxide and its vasorelaxant effect in rats. Acta Pharmacol Sin 29: 923-930.

FABER GM, SILVA J, LIVSHITZ L \& RUDY Y. 2007. Kinetic properties of the cardiac L-type Ca2+ channel and its role in myocyte electrophysiology: a theoretical investigation. Biophys J 92: 1522-1543.

GREENSTEIN JL, TANSKANEN AJ \& WINSLOW RL. 2004. Modeling the actions of beta-adrenergic signaling on excitation-contraction coupling processes. Ann NY Acad Sci 1015: $16-27$.

GUO D, YOUNG L, WU Y, BELARDINELLI L, KOWEY PR \& YAN GX. 2010. Increased late sodium current in left atrial myocytes of rabbits with left ventricular hypertrophy: 
its role in the genesis of atrial arrhythmias. Am J Physiol Heart Circ Physiol 298: H1375-1381.

HEATHER LC, CATCHPOLE AF, STUCKEY DJ, COLE MA, CARR CA \& CLARKE K. 2009. Isoproterenol induces in vivo functional and metabolic abnormalities: similar to those found in the infarcted rat heart. J Physiol Pharmacol 60: 31-39.

HERMANN A, SITDIKOVA GF \& WEIGER TM. 2012. Gasotransmitters: Physiology and Pathophysiology. Springer, p. 1-96.

HUANG Y ET AL. 2016a. Endogenous sulfur dioxide alleviates collagen remodeling via inhibiting TGF-beta/ Smad pathway in vascular smooth muscle cells. Sci Rep 6: 19503.

HUANG Y, TANG C, DU J \& JIN H. 2016b. Endogenous Sulfur Dioxide: A New Member of Gasotransmitter Family in the Cardiovascular System. Oxid Med Cell Longev 2016: 8961951.

JIN HF, DU SX, ZHAO X, WEI HL, WANG YF, LIANG YF, TANG CS \& DU JB. 2008. Effects of endogenous sulfur dioxide on monocrotaline-induced pulmonary hypertension in rats. Acta Pharmacol Sin 29: 1157-1166.

KAMOUN P. 2004. Endogenous production of hydrogen sulfide in mammals. J Amino Acids 26: 243-254.

LIANG Y, LIU D, OCHS T, TANG C, CHEN S, ZHANG S, GENG B, JIN H \& DU J. 2011. Endogenous sulfur dioxide protects against isoproterenol-induced myocardial injury and increases myocardial antioxidant capacity in rats. Lab Invest 91: $12-23$.

LIU D, JIN H, TANG C \& DU J. 2010. Sulfur dioxide: a novel gaseous signal in the regulation of cardiovascular functions. Mini Rev Med Chem 10(11): 1039-1045.

LUO L, CHEN S, JIN H, TANG C \& DU J. 2011. Endogenous generation of sulfur dioxide in rat tissues. Biochem Biophys Res Commun 415: 61-67.

MENG Z. 2003. Oxidative damage of sulfur dioxide on various organs of mice: sulfur dioxide is a systemic oxidative damage agent. Inhal Toxicol 15: 181-195.

MENG Z \& LIU Y. 2007. Cell morphological ultrastructural changes in various organs from mice exposed by inhalation to sulfur dioxide. Inhal Toxicol 19: 543-551.

MORALES D, HERMOSILLA T \& VARELA D. 2019. Calciumdependent inactivation controls cardiac L-type Ca (2+) currents under $\beta$-adrenergic stimulation. J Gen Physiol 151: 786-797.

NIE A \& MENG Z. 2005a. Study of the interaction of sulfur dioxide derivative with cardiac sodium channel. Biochim Biophys Acta 1718: 67-73.
NIE A \& MENG Z. 2005b. Sulfur dioxide derivative modulation of potassium channels in rat ventricular myocytes. Arch Biochem Biophys 442: 187-195.

NIE A \& MENG Z. 2006. Modulation of L-type calcium current in rat cardiac myocytes by sulfur dioxide derivatives. Food Chem Toxicol 44: 355-363.

NIE A \& MENG Z. 2007. Sulfur dioxide derivatives modulate $\mathrm{Na} / \mathrm{Ca}$ exchange currents and cytosolic [Ca2+]i in rat myocytes. Biochem Biophys Res Commun 358: 879-884.

ŞENGÜL AS, SIRCAN AK, ABEWA M, KURT A, DALAMAN U \& YARAŞ N. 2020. Mathematical model of the ventricular action potential and effects of isoproterenol-induced cardiac hypertorphy in rats. Eur Biophys J 49: 323-342.

SHAPIRO R. 1977. Genetic effects of bisulfite (sulfur dioxide). Mutat Res 39: 149-175.

SINGER TP \& KEARNEY EB. 1956. Intermediary metabolism of L-cysteinesulfinic acid in animal tissues. Arch Biochem Biophys 61: 397-409.

STIPANUK MH. 1986. Metabolism of sulfur-containing amino acids. Annu Rev Nutr 6: 179-209.

STIPANUK MH. 2004. Sulfur amino acid metabolism: pathways for production and removal of homocysteine and cysteine. Annu Rev Nutr 24: 539-577.

SUN Y ET AL. 2010. Effects of sulfur dioxide on hypoxic pulmonary vascular structural remodeling. Lab Invest 90: 68-82.

ZHANG Q \& MENG Z. 2012. The negative inotropic effects of gaseous sulfur dioxide and its derivatives in the isolated perfused rat heart. Environ Toxicol 27: 175-184.

ZHANG RY, DU JB, SUN Y, CHEN S, TSAI HJ, YUAN L, LI L, TANG CS \& JIN HF. 2011. Sulfur dioxide derivatives depress L-type calcium channel in rat cardiomyocytes. Clin Exp Pharmacol Physiol 38: 416-422.

ZHAO X, JIN HF, TANG CS \& DU JB. 2008. Effects of sulfur dioxide, on the proliferation and apoptosis of aorta smooth muscle cells in hypertension: experiments with rats. Zhonghua Er Ke Za Zhi 88: 1279-1283.

\section{SUPPLEMENTARY MATERIAL}

\section{Figures S1-S4 and Table SI}




\section{How to cite}

DALAMAN U, ÖZDOĞAN H, SIRCAN AK, ŞENGÜL SA \& YARAŞ N. 2021. Sulfur Dioxide Derivative Prevents the Prolongation of Action Potential During the Isoproterenol-Induced Hypertrophy of Rat Cardiomyocytes. An Acad Bras Cien 93: e20201664. DOI 10.1590/0001-3765202120201664.

Manuscript received on October 23, 2020;

accepted for publication on February 10, 2021

\section{UĞUR DALAMAN ${ }^{1}$}

https://orcid.org/0000-0001-7145-4139

\section{HASAN ÖZDOĞAN ${ }^{1,2}$}

https://orcid.org/0000-0001-6127-9680

\section{AHMED K. SIRCAN ${ }^{3}$}

https://orcid.org/0000-0002-2720-7023

\section{SEVGI A. ŞENGÜL ${ }^{4}$}

https://orcid.org/0000-0003-0083-4446

\section{NAZMI YARAŞ ${ }^{1}$}

https://orcid.org/0000-0002-9450-2698

${ }^{1}$ Akdeniz University, Medical Faculty, Department of Biophysics, Dumlupınar Blv., 07070 Antalya, Turkey

${ }^{2}$ Antalya Bilim University, Vocational School of Health Services, Akdeniz Blv. No: 90, 07085 Antalya, Turkey

${ }^{3}$ Antalya Bilim University, Electrical and Computer Engineering, Akdeniz Blv. No: 90, 07085 Antalya, Turkey

${ }^{4}$ Antalya Bilim University, Industrial Engineering, Akdeniz Blv. No: 90, 07085 Antalya, Turkey

Correspondence to: Nazmi Yaraş

E-mail:nazmiyaras@akdeniz.edu.tr

\section{Author contributions}

UD: conceptualized, designed and performed the experiments, analyzed the data and drafted the manuscript. HÖ: analyzed the data, mathematical modelling and performed graphical work. AKS and SAŞ: performed mathematical modelling and analyzed the data. NY: conceptualized, designed and performed the experiments, analyzed the data, wrote and edited the manuscript.

\section{(cc) BY}

